Hispania Sacra, LVIII

118, julio-diciembre 2006, 489-515, ISSN: 0018-215-X

\title{
LA EUCARISTÍA EN EL CORAZÓN DEL SIGLO XVI*
}

\author{
POR \\ SOLEDAD GÓMEZ NAVARRO \\ Profesora Titular de Historia Moderna, Universidad de Córdoba
}

\begin{abstract}
RESUMEN
En el centro mismo del Quinientos la Eucaristía se convirtió en un verdadero problema teológico. A través de dos importantes obras de la época, este es el principal objetivo del presente artículo, analizar aquel sacramento desde las distintas interpretaciones teológicas al respecto, básicamente protestantismo y catolicismo, como es obvio. Montado sobre el estudio encargado de dos obras de la época, consta y examina, por tanto, tres partes indispensables, a saber: El ambiente de la Europa de la época; con detalle el concilio de Trento por ser, precisamente, el centro mismo de una de las dos publicaciones interesadas en este trabajo; y la misma Eucaristía en el debate teológico, también justamente la temática monográfica del segundo libro sobre el que gira la presente aportación.
\end{abstract}

PALABRAS ClAVE: Iglesia, Europa, Siglo XVI, Eucaristía, Luteranismo, Calvinismo, Anglicanismo, Catolicismo, concilio de Trento.

\section{ABSTRACT}

In right the middle of the sixteenth century the Eucharist turned out to be an important theological problem. The main goal of this essay is to analyze the above mentioned Sacrament by analyzing several relevant literary texts from the several theological interpretations that appeared at the time, and as obvious I will

* Este artículo tuvo su origen en el Proyecto de Investigación BHA2003-08909-C03-01, financiado por el Ministerio de Ciencia y Tecnología (MCyT) con fondos FEDER (Fondo Europeo de Desarrollo Regional) y PGE (Presupuesto General del Estado). Por otra parte, forma parte del trabajo redactado para la elaboración del Catálogo sobre la exposición «Martiria» que el pasado año 2005 y en torno a los Mártires cordobeses y el sacramento de la Eucaristía la Diócesis de Córdoba pensó montar para la celebración del XVII Centenario de los Santos Mártires de Córdoba en el Año de la Eucaristía; preparado por expreso encargo del comisario de dicha exposición, el Profesor Titular de la Universidad de Córdoba Fernando Moreno Cuadro. 
be basically focusing on the Catholic and Protestant frames of mind. Our study is based on the study of two works of the period, and it analyzes three fundamental parts, that is to say: the cultural and social atmosphere of Europe in that period, paying special attention to the Council of Trent. I am doing so because this Council is at the very center of one of the two publications I am dealing with in this paper. I am also paying especial attention to the Eucharist within the theological debate, which is the monographic theme in the second book about which this publication is centered.

KEY WORDS: Church, Europe, XVI Century, Eucharist, Lutheranism, Calvinism, Anglicanism, Catholicism, Council of Trent.

Este estudio sobre la Eucaristía, un problema verdaderamente importante en el corazón mismo del siglo XVI, tiene como base dos obras claves para aquélla y su resolución definitiva, al menos para el Catolicismo en Trento, como son Concilium Tridentinum ${ }^{1}$ y Veritate Christi ${ }^{2}$, cuyo análisis se nos encomendó para la elaboración del Catálogo de una exposición, como también asimismo ya se ha explicado. De ahí, pues, las tres partes inextricablemente unidas que lo conforman: el indispensable análisis del contexto en que se va a producir una de las más importantes etapas de la Historia de la Iglesia, si no la más importante; el examen minucioso del Concilio de Trento, núcleo de la primera publicación propuesta; y, por supuesto, el desbrozamiento detallado del debate teológico suscitado en torno a la Eucaristía, y desarrollado a partir precisamente de Veritate Christi, la fundamental obra de Mouchy.

\section{UNA IGLESIA EN CRISIS Y DIVIDIDA, UNA EUROPA EN GUERRA}

Cuando el 13 de diciembre de 1545 se abría y desarrollaba la primera sesión pública del Concilio de Trento, la Iglesia occidental dejaba atrás más de dos siglos de gran decadencia, doctrinal, teológica y sobre todo moral, probablemente de las más importantes de su ya entonces dilatada historia por su profundidad y prolongación. El Cisma de Avignon; el Gran Cisma de Occidente, durante el cual llegaron a coincidir tres Papas, en la ciudad francesa, en Roma y en Pisa, lo que originará gran desorientación, reproches y censuras; el Concilio de Constanza que puso fin a aquél con la elección de Martín V; el de Basilea, en que se

${ }^{1}$ Lovanii, Apud Petrum Zangrium Tiletanum, sub Fonte, 1567, 2 partes. Fol. Biblioteca Pública de Córdoba (BPC), 614: 9-224, según M. IGLESIAS TAIS y A. FloREs MuÑoz, Catálogo de Incunables e impresos del siglo XVI de la Biblioteca Pública de Córdoba, Córdoba, 1986, pp. 110-111.

2 Antoine de Mouchy, De Veritate Christi, nec non corporis et sanguinis eius in Missae sacrificio, adversus haereticos assertio. Divinae Scripturae, sacrorum Conciliorum, ac Sanctorum Doctorum testimoniis amplissime confirmata, Parisiis, Apud Nicolaum Chesneau, 1570, 8 h., 153 f., 8. . : BPC 1500: 37-28, según M. Iglesias TAis y A. Flores MuÑoz, Ibid.., p. 249.

Hispania Sacra, LVIII

118, julio-diciembre 2006, 489-515, ISSN: 0018-215-X 
afirmó como dogma la supremacía conciliar, y que, por tanto, ponía de primera actualidad el conciliarismo; o la concesión en 1478 y por Sixto IV de la Bula Dum fructus uberes, que autorizaba a los franciscanos la aceptación de legados testamentarios, por citar sólo algunos de los hitos más conocidos, no son sino la punta del iceberg de una extensa y variada problemática, los males de la vieja Iglesia, que ya asolaban desde hacia tiempo a la Cristiandad, y entre los que destacaban los siguientes $^{3}$ : El debilitamiento de la organización eclesiástica y la decadencia del prestigio papal; la pérdida de la autoridad política, administrativa y económica de la Iglesia pese a su gran riqueza acumulada en la época medieval y bajomedieval; el aumento y la acumulación de beneficios en una misma persona, pese a lo cual persistía el frecuente absentismo de los oficios/ beneficios, e incluso cesión hereditaria, a veces de padres a hijos.

Asimismo, los servicios políticos de la jerarquía eclesiástica, sobre todo en Francia y en Alemania; los abusos de la curia romana, especialmente en lo referido a beneficios y a la centralización fiscal; el aumento del proletariado eclesiástico, de graves consecuencias para la corrección del clero; la inmoralidad de los clérigos y la jerarquía eclesiástica —-simonía, sodomía, concubinato, nepotismo...; la relajación de la disciplina del alto y bajo clero, y tanto secular como regular - inobservancia de reglas y Constituciones-, así como la deficiente instrucción religiosa, en este caso también entre los laicos; la inmoralidad pública en materia de hijos ilegítimos; el divorcio entre la jerarquía y el cuerpo de los fieles, pese a la fuerte religiosidad popular imantada por su adhesión a jubileos y peregrinaciones, devoción mariana, e indulgencias; el abuso de las excomuniones; el negocio de las indulgencias y las reliquias; la mundanidad de los Papas y su contagio de la cultura renacentista, lo que empieza a provocar crítica mordaz a lo religioso; la proliferación de visionarios, extáticos y herejes; y el dominio de un escolasticismo vacuo y artificioso, vertido en cuestiones sutiles y disquisiciones infructuosas ${ }^{4}$.

En el tránsito de la medievalidad a la modernidad, y en un ambiente dominado por el nacimiento del capitalismo, el arranque de los grandes descubrimientos geográficos, la recuperación demográfica, la revitalización de la burguesía, el resquebrajamiento del sistema feudal, la inestabilidad social en el medio rural, la emersión del Estado moderno, la subordinación de la Iglesia al Estado, el nominalismo, el humanismo, el individualismo y el antropocentrismo, y el inicio del laicismo y la secularización, con su correspondiente crítica y cuestionamiento del principio de autoridad, e incipiente cultura de élites aunque éstas sean eclesiásticas ${ }^{5}$, toda la extensa y diversa problemática indicada suscita distintas expresiones, manifestaciones, reacciones o respuestas por todo el obre cristiano y de muy diferente índole, a saber:

\footnotetext{
${ }^{3}$ R. Romano y A. Tenenti, Historia..., 12, pp. 204-8.

4 Jacques Delumeau, La reforma, pp. 5-28. J. LoRTZ, Historia de la..., II, pp. 47-95.

5 Joseph LoRTZ, Historia de la..., I, pp. 481-534.
} 
El misticismo de Alemania y Países Bajos con su defensa del contacto directo con Dios y la propia experiencia espiritual; Wyclif y Hus con su antijerarquismo y críticas del sistema eclesiástico; el conciliarismo o teoría conciliarista, general en el resurgir del campo mismo de la teología y como consecuencia de los prenotados abusos eclesiásticos, especialmente si del Papa se trataba, y según la cual se considera al concilio general portador de la máxima potestad en la Iglesia, a la que también aquél está sometido; Kempis; la «Devotio Moderna», creada por Gerardo Groot, difundida por, entre otros, Lefévre d'Etaples, practicada por Erasmo de Rotterdam, Lutero, Zwinglio, Calvino, o san Ignacio de Loyola, y dirigida al conocimiento de Dios mediante una experiencia íntima y personal; los Hermanos de la Vida en Común, expresión práctica comunitaria de la misma «devoción moderna»; Erasmo y la oleada de evangelismo o paulinismo; el impulso hacia la Reforma en España por los Reyes Católicos - focos de Alcalá de Henares, Salamanca, Valladolid; personalidades de Cisneros, los Valdés, Luis Vives, Miguel de Eguía, san Juan de Ávila; creación de la Inquisición, etc...; el concilio Lateranense $\mathrm{V}$ desarrollado en el crucial quinquenio de 1512 a 1517, y de tan importantes medidas sobre organización eclesiástica y disciplina como de nula e ineficaz aplicación; el mismo protestantismo - Lutero, Zwinglio, Calvino, Melanchton, Bucer, Münzer, Enrique VIII, y tantos otros-, hijo del nuevo espíritu moderno y del Humanismo en cuanto tiene de subjetivismo, libre examen e interpretación de las Sagradas Escrituras; el iluminismo o alumbradismo; la fundación de la Compañía de Jesús; la aparición de una nueva piedad en los pronto y rápidamente populares Oratorios de Amor Divino de San Felipe Neri; la misma convocatoria del concilio de Trento; la generalizada, constante y prolongada petición, en suma, de la necesidad de reforma «in capite et in membris», y del sentido de ésta, cuya concreción más axial para el desgarro que ya estaba sufriendo la Cristiandad iba a ser precisamente Trento ${ }^{6}$.

Todavía a mediados del Quinientos y en pleno concilio de Trento se desarrollan la Transacción de Passau, tras el espejismo de victoria sobre el protestantismo en Mühlberg; la firma de la Paz de Augsburgo, consagración jurídica de la escisión religiosa y de la uniformidad de fe imperante en los territorios luteranos en el mismo principio «cuius regio eius religio»; los brotes luteranos de Valladolid y Sevilla y sus correspondientes Autos de fe resolutivos; nuestro primer Índice de libros prohibidos; la consolidación del puritanismo; o el cenit de la ascética y la mística de fray Luis de León, fray Luis de Granada, san Juan de la Cruz y santa Teresa de Jesús. Y aun después de clausurado aquél, y ya en el Seiscientos y Setecientos, aparecerían el jansenismo, el pietismo, el deísmo.

${ }^{6}$ M. Bataillon, Erasmo y..., pp. 1-71, 103-225. R. Romano y A. Tenenti, Historia..., 12, pp. 196225. José Orlandis, Historia de la..., I, pp. 383-438. F. Martín Hernández, Historia de la..., II, pp. 11-54.

Hispania Sacra, LVIII

118, julio-diciembre 2006, 489-515, ISSN: 0018-215-X 
Afectada naturalmente por el mismo tránsito de época y por la misma convulsa primera Edad Moderna, como hemos visto, la Iglesia, ese gran sistema cultural, omnicomprensivo, globalizador, universal y universalista, con afán controlador total por $\operatorname{tanto}^{7}$, a fines del XVI, y desde luego el 4 de diciembre de 1563 cuando termina la magna y bastante perdurable cita tridentina, se había astillado indefectiblemente, iniciándose además una larga, traumática y terrible contienda, cuyo último episodio, al menos de punto y seguido, sería la guerra de los Treinta Años.

\section{Un hito CATólico A MEdidAdos DEL XVI: El CONCILIO DE TRENTO}

Un verdadero clamor en el seno de toda la Cristiandad como ya se ha dicho, el Concilio de Trento fue el decimonono de la Iglesia católica, testigo de cuatro Papados, tres periodos sucesivos aunque interrumpidos de trabajos por motivos bélicos, sanitarios y sobre todo intelectuales, y veinticinco sesiones. marcado por las cuestiones y tensiones teológicas y también sin duda políticas de la Europa de su tiempo; y especialmente significativo no sólo por su condena de las Iglesias reformadas, sino también por su transcendencia para la Iglesia Católica Apostólica y Romana en materia teológica, doctrinal y moral durante mucho tiempo ${ }^{8}$. Veamos ahora los prolegómenos de la convocatoria, su desarrollo y repercusión de esta nuclear cita de la reforma religiosa del siglo XVI, cuyo estudio ha generado muy amplia y diversa historiografía 9 .

Como es sabido, desde la Dieta de Wörms en 1521 con su condena de Martín Lutero, insistentes voces de distinta procedencia y talante reclamaron reiteradamente la realización de un concilio. En la Dieta de Nuremberg de 15221523 todos los estamentos imperiales alemanes exigieron un concilio cristiano libre en tierra alemana, reivindicación, empero, rechazada por Roma, pues la táctica de Clemente VII (1523-1534) fue eludir la confrontación con el problema. Temía que en el marco de un concilio se planteasen exigencias de una reforma demasiado radical y la impugnación de su elección papal a causa de su condición de hijo ilegítimo. A ello se agregaron los enfrentamientos entre Carlos $\mathrm{V}$ y el rey francés Francisco I. En la coronación imperial del primero, en la Bolonia de 1530, Clemente VII respondió afirmativamente a la petición de convocar un concilio, pero asoció a tal convocatoria condiciones que, en la práctica, la hacían imposible.

\footnotetext{
7 R. Romano y A. TEnEnTI, Ibid., pp. 71-73.

8 M. Teruel Gregorio de Tejada, Manual..., p. 95. E. Martínez Ruiz (Dir.), Diccionario de..., pp. 85-86.

9 E. DenZINGer, El magisterio de la..., pp. 222-283. Hubert Jedin, Historia del..., 1972-1981, 4 vols. Jacques Delumeau, El catolicismo de..., pp. 6-52. B. LlorCA, «Participación de...», pp. 387-503. C. Gutiérrez, Trento: Un..., III. J. LorTz, Historia de la..., II, pp. 203-216.
} 
Su sucesor en la sede de San Pedro, Paulo III (1534-1549), reconoció que la publicación de un concilio era ya ineludible. Con ocasión de una estancia de Carlos V en Roma en 1536 se acordó la realización del mismo, convocándose para el 23 de mayo de 1537 en Mantua a través de una bula fechada el 2 de junio del año anterior. Pero este intento fallaría por el rechazo de Francia ante su interés por oponerse a Carlos $\mathrm{V}$, también las estrategias del rey inglés Enrique VIII para impedirlo, y la negativa a participar de la Liga de Esmalcalda. Por si todo ello fuera poco, las amplias condiciones exigidas por el duque de Mantua para la realización del concilio hicieron que la convocatoria fuese trasladada a Vicenza -8 de octubre de 1537 - Los legados papales esperaron inútilmente que se les enviara. El 21 de mayo de 1539 el concilio fue suspendido ad beneplacitum, y en el tiempo subsiguiente Carlos V llevó adelante una política de reunión a través de coloquios de religión en Hagenau, Wörms y Ratisbona.

Al fracasar la unión con los protestantes en la Dieta de Ratisbona de 1541, Paulo III retomó el plan de celebrar un concilio. El 22 de mayo de 1542 estableció que éste se iniciase el día de la fiesta de Todos los Santos de ese año en Trento, emplazamiento aceptado por los estamentos imperiales, y enviándose como legados a Pietro Paolo Parisio, Giovanni Morone y Reginald Pole, éste último, de formación erasmista, precisamente uno de los aludidos en la obra Concilium Tridentinum. No obstante, sólo se presentaron unos pocos prelados. El emperador y el Papa no pudieron superar las tensiones que los separaban, debidas, entre otras razones, a la neutralidad del segundo en los enfrentamientos del primero con Francia. En tal situación no cabía otra salida: Paulo III suspendió otra vez el concilio el 6 de julio de 1543 sin fijar una nueva fecha.

Tras su victoria sobre Francisco I, Carlos V se comprometió en la paz de Crépy de 1544 a enviar una delegación a un concilio que debía celebrarse en Trento, Cambrai o Metz. A continuación, Paulo III convocó el 19 de noviembre de 1544 el concilio para el 15 de marzo del año siguiente en Trento, designando las tareas que debía cumplir, a saber: La superación de la división religiosa, a la sazón, ya una práctica realidad —en 1546 muere Lutero y un año después Enrique VIII, por ejemplo- - la reforma de la Iglesia y la liberación de los cristianos que estaban bajo la dominación de los no creyentes. El plan de Carlos V era someter primero militarmente a los protestantes y obligarlos entonces a participar en el concilio; por lo mismo, la decisiones conciliares deberían ser llevadas a cabo por causa del mismo imperio, restableciéndose así la unidad religiosa. Imbuido de un espíritu confiado de inspiración paulinista que inspiraría todo el concilio, y oponiéndose en todo su despliegue a las principales doctrinas protestantes, a saber, justificación por la fe, sacerdocio universal, infalibilidad basada tan sólo en la Biblia, libre albedrío, y únicamente dos solos sacramentos, su primer periodo de sesiones ocuparía el trienio 1545-1548. 
En efecto, y como ya apunté más arriba, tras una prolongada demora, el concilio fue inaugurado el 13 de diciembre de 1545 en la catedral de Trento, según la bula Indictionis sacri oecumenici et generalis Concilii Tridentini, emitida por Paulo III en San Pedro el 11 de junio de 1543. Los legados papales fueron Giovanni María del Monte — más tarde Julio III-, Marcello Cervini — después Marcelo II- y el ya citado y conocido Reginald Pole. Tenían derecho a voto los obispos presentes - también los titulares, esto es, cuya teórica sede estaba in partibus infidelium - , y los superiores de las órdenes religiosas —en el caso de los abades, los representantes de las congregaciones monásticas-, pero no los procuradores presentes. La cuestión sobre si debían ser tratados prioritariamente los asuntos dogmáticos o los de reforma fue zanjada el 22 de enero de 1546 decidiéndose tratar ambos de forma paralela, determinación no aprobada por Paulo III pero que se siguió a lo largo de todo el concilio.

El procedimiento establecido por el concilio consistió en tres pasos. Primero, los teólogos conciliares sin derecho a voto preparaban los textos dogmáticos en las reuniones de teólogos. En la mayoría de los casos tomaron como punto de partida tesis de los reformadores, a veces, extraídas de su contexto. En segundo lugar, los proyectos eran presentados por los legados papales a los padres conciliares con derecho a voto en las reuniones plenarias para que se tratasen y votasen. En base a las modificaciones propuestas, los textos eran reformulados en las comisiones creadas a ese propósito y se votaban hasta que se producía una mayoría. En tercer lugar, y finalmente, los cánones y decretos doctrinales y de reforma eran publicados en las sesiones solemnes.

Los textos dogmáticos estuvieron orientados al enfrentamiento con los reformadores. En el primer periodo de sesiones se despachó una serie de importantes decretos. En el decreto sobre la aceptación de los sagrados libros y tradiciones se afirma que la verdad revelada se encuentra contenida in libris scriptis et sine scripto traditionibus, esto es, Sagradas Escrituras y tradición, por lo que los libros bíblicos, es decir, el canon completo del Antiguo y Nuevo Testamentos, así como las tradiciones transmitidas por los apóstoles referidas tum ad fidem, tum ad mores — fe y costumbres_-, han de ser recibidos pari pietatis affectu. Sin libre interpretación de las Escrituras por supuesto, se reconoce la Vulgata Latina como texto auténtico, o sea, como texto con fuerza probatoria en el ámbito teológico, pero su utilización no debía impedir el estudio de las lenguas bíblicas originales — sesión IV, 8 de abril de 1546-.

En el decreto sobre el pecado original — sesión V, 17 de junio de 1546- se rechazó la doctrina luterana de la concupiscencia. La concepción presentada por Girolamo Seripando influenciada por San Agustín, según la cual la concupiscencia podía designarse en cierto sentido como pecado por ser consecuencia y castigo del pecado original, raíz y causa de muchos pecados, y ya por su sola existencia un impedimento para el cumplimiento perfecto de la ley de Dios, no 
fue aceptada por ser demasiado afín a la de los reformadores. En la misma sesión los padres conciliares aceptaron un decreto sobre la erección de lectorados de Sagrada Escritura en las iglesias catedrales y colegiatas, modo por el cual se elevaría el nivel de formación de los sacerdotes.

La sesión VI despachó el decreto sobre la justificación -13 de enero de 1547-, resultado de largas y difíciles discusiones con numerosos proyectos. El cardenal Pole renunció a su cargo en octubre de 1546 sobre todo por su descontento con el trabajo en el decreto sobre la justificación, al pensar que se tuvo demasiado poco en cuenta la imputación de la justicia de Cristo en el perdón de los pecados. Las inquietudes de Seripando, cuya participación fue determinante en la redacción de varios proyectos, fueron en su mayoría rechazadas. Según él, la justificación consiste sobre todo en que el pecador es unido a Jesucristo. Por la fe se perdona al pecador su pecado en cuanto se le comunica y aplica la justicia de Cristo. La caritas, regalo de Dios, capacita al ser humano para obrar bien. Pero como el hombre sólo logra practicar una justicia imperfecta, la justifica infusa es complementada a través de la aplicación de la justicia de Cristo. Se trata aquí de la llamada «doble Justicia». El decreto definitivo declara en 16 capítulos doctrinales y 33 cánones, como recoge Concilium Tridentinum, que el hombre puede merecer por sí mismo la gracia de la justificación, pero debe obrar aceptando la acción de Dios. La justificación consiste en la santificación y renovación del hombre interior. En la justificación, cuya causa instrumental es el bautismo, se infunde en los hombres la fe, la esperanza y el amor. La fe es el inicio de la salvación humana, la base y la raíz de la justificación. La gracia de la justificación puede crecer a través de la fe y las buenas obras. La gracia de la justificación que se ha perdido puede recuperarse a través de la penitencia. A pesar de todos sus méritos, el decreto tiene ciertas unilateralidades y lados débiles. En la misma sesión se despachó un decreto sobre la obligación de residencia de los obispos y párrocos, que tuvo considerable oposición al no tener en cuenta la posibilidad de exenciones y dispensas papales.

La sesión VII, 3 de marzo de 1547, publicó un decreto sobre los sacramentos en general, es decir, sobre el concepto de sacramento - sacramento como signo eficaz-, sobre su número de siete, y sobre los del bautismo y la confirmación. Un decreto de reforma prohibió la acumulación de beneficios o prebendas y recortó determinadas exenciones.

Algunos presuntos casos de fiebre tifoidea en Trento hicieron que en la sesión VIII, 11 de marzo de 1547, los legados resolvieran el traslado del concilio a Bolonia, a lo que se negaron los 14 obispos imperiales. Allí se siguió tratando sobre los sacramentos, la misa y las medidas necesarias de reforma pero, a raíz de la oposición imperial, el Papa indicó que se no se aprobaran nuevos decretos. Carlos V presentó en Bolonia y Roma una solemne protesta por el traslado del concilio, y Paulo III dispuso el 3 de febrero de 1548 de forma extraoficial la 
suspensión de las tareas conciliares, suspensión que publicó oficialmente el 14 de septiembre de 1549 .

Se abriría, pues, el segundo periodo de sesiones dos año después (15511552).

Respondiendo a las exigencias de Carlos V, el sucesor de Paulo III, Julio III (1550-1555), convocó nuevamente el concilio para el 1 de mayo de 1551 en Trento. Por oposición a Carlos V, Francia adoptó una actitud de rechazo. La presidencia del concilio fue ejercida por el cardenal Marcello Crescenzio, el arzobispo Sebastiano Pighino, y el obispo Luigi Lippomani. Para participar los protestantes exigieron que el concilio no estuviera bajo la dirección del Papa y que los decretos del primer periodo fuesen tratados de nuevo sobre la base del principio de sola scriptura. Wurtemberg, Estrasburgo y los electorados de Sajonia y Brandeburgo enviaron legaciones a Trento, que, sin embargo, no entraron en negociaciones con los participantes en el concilio. Alemania tuvo una representación relativamente importante en este periodo de sesiones encarnada en los tres arzobispos renanos, once obispos, y, como teólogos, Johannes Gropper y Eberhard Billick. Estuvieron también presentes teólogos de la Universidad de Lovaina, ciudad precisamente de publicación de Concilium Tridentinum, el libro núcleo de este trabajo, y de los Países Bajos.

Sobre la base de las tareas previas llevadas a cabo en Bolonia, en la sesión XIII, 11 de octubre de 1551, se pudo despachar un decreto precisamente sobre la doctrina de la Eucaristía, como veremos después, con la definición de la presencia real y de la transubstanciación. En cambio, los artículos sobre la comunión bajo ambas especies fueron postergados hasta la llegada de los protestantes. La sesión XIV, 25 de noviembre de 1551, publicó un decreto sobre el sacramento de la penitencia en el que se destacaba la necesidad de la confesión individual, el carácter judicial de la solución y la satisfacción por el pecado cometido. Otro decreto trató acerca de la sacramentalidad de la unción de los enfermos. Un decreto de reforma reglamentó las exigencias para la recepción de la ordenación, el deber de vigilancia de los obispos sobre la forma de vida de los clérigos, y cuestiones concernientes a la provisión de beneficios.

La conspiración de los príncipes alemanes contra el emperador y los acontecimientos bélicos que la misma suscitó provocaron una nueva suspensión del concilio — sesión XVI, 28 de abril de 1552—. Julio III tuvo la intención de publicar una serie de decretos de reforma aún no confirmados por el concilio porque España y Portugal querían ponerlos en práctica por su propia cuenta, pero no logró concretar su iniciativa.

Los esfuerzos realizados más tarde por Paulo IV (1555-1559) para llevar a cabo una reforma de la Iglesia con ayuda de una comisión pontificia de reforma y de un planeado concilio que se realizaría bajo la supervisión papal en Roma, 
también resultaron infructuosos. Se llega así al tercer y último periodo de sesiones del concilio de Trento bajo Pío IV (1559-1565).

Para entonces en Francia el calvinismo había realizado grandes progresos, presentándose la amenaza de un concilio nacional francés; incluso una reunión del clero en Poissy - Coloquio de religión del 9 de septiembre al 9 de octubre de 1561 - estuvo cerca de constituir un sínodo semejante. Francia y el nuevo emperador Fernando I exigieron la convocatoria de un nuevo concilio, mientras que Felipe II de España insistió en la prosecución del anterior, controversia que eludió la bula de convocatoria emitida por Pío IV el 29 de noviembre de 1560. Los estamentos protestantes alemanes rechazaron una vez más el 5 de febrero de 1561, en la Asamblea de Príncipes de Naumburgo, el envío de delegados al concilio, cuya tercera apertura acaeció el 18 de enero del año siguiente, siendo legados papales en la primera fase de este último periodo Ercole Gonzaga, Seripando, Stanislaus Hosius y Ludovico Simonetta.

Como el sector imperial había opuesto su veto a la continuidad del concilio, sólo se trataron al comienzo cuestiones de reforma. Se retomó también el problema de la obligación de residencia de los obispos y párrocos. Los españoles, los obispos del territorio de soberanía imperial y algunos obispos italianos exigieron que la residencia debiera declararse como obligatoria de iure divino, de forma que no existiese ya ninguna posibilidad de simple dispensa, exigencia, empero, que en la votación no alcanzó por pocos votos la mayoría. El Papa prohibió la prosecución del debate sobre la residencia, y el problema fue pospuesto hasta que se tratase el decreto sobre el orden sagrado.

Al haber cedido la resistencia de los franceses y de Fernando I contra la continuación del concilio, se retomó la consideración de las materias aún intratadas. Así, la sesión XXI, 16 de julio de 1562, despachó un decreto sobre la comunión bajo ambas especies en el que se afirmaba que los laicos y los sacerdotes no celebrantes no están obligados por derecho divino a la comunión con el cáliz — comunión bajo ambas especies para los laicos, como veremos después-, y que Cristo está presente de forma plena y completa bajo cada una de las especies. Tras una fuerte controversia se asumió en la sesión XXII, 17 de septiembre de 1562, el decreto sobre el sacrificio de la Misa, definiéndose éste como verdadero y auténtico sacrificio. Es el verdadero sacrificio de expiación por los vivos y los muertos, pero no un nuevo sacrificio, sino repraesentatio, memoria y applicatio del sacrificio de la cruz. El sacrificio de la cruz y el de la misa son idénticos; sólo el modo del sacrificio — ratio offerendi-es diferente. Ahora bien, el concilio no logró dar una fundamentación convincente de la unidad entre sacrificio de la cruz y sacrificio de la misa. La petición de Fernando I y del duque de Baviera de conceder la comunión bajo ambas especies para sus respectivos territorios fue dejada por el concilio a la decisión del Papa, quien otorgó después del concilio un indulto a propósito de la comunión bajo ambas 
especies con vigencia para Alemania, Austria, Bohemia y Hungría el 16 de abril de 1564.

En noviembre de 1562 se presentaron al concilio trece obispos franceses bajo la dirección del cardenal Carlos Guisa. Su aparición agudizó los enfrentamientos eclesiológicos, ya completamente encendidos en las discusiones en torno al decreto sobre el orden sagrado y al problema de la obligación de residencia, cuya discusión se había retomado. Se trató acerca de la esencia del ministerio episcopal, de su posición dentro de la jerarquía y de la esencia y el alcance del primado papal. Como los franceses rechazaron la fórmula del primado que decía que el Papa era universalis ecclesiae episcopus, mantuvieron la afirmación de la superioridad del concilio respecto del Papa o conciliarismo, como sabemos, y, junto con la mayoría de los obispos españoles, afirmaron que la residencia del obispo era obligatoria tanto por derecho humano como divino, el concilio entero entró en enero de 1563 en un callejón sin salida; situación a que se agregó en marzo del mismo año la muerte de los esforzados y notorios legados Gonzaga y Seripando.

La negociación de Guisa con el emperador en febrero de 1563 en Innsbruck acarreó el envío por Fernando I el 3 de marzo de 1563 de dos cartas al Papa, invitándole a acudir en ayuda del concilio. El inefable cardenal Morone, que había sido nombrado primer legado del concilio, viajó a Innsbruck en abril-mayo de ese significativo año de 1563, obteniendo el apoyo del emperador, y más tarde también el de Guisa, para una solución de compromiso consistente en excluir del debate la determinación de la esencia del ministerio episcopal y la relación entre episcopado y primado papal, para apuntar a una profunda reforma eclesiástica. Por eso el decreto sobre el orden sagrado despachado en la sesión XXIII, 15 de julio de 1563, lleva los rasgos de una solución teológica de compromiso. Se define la sacramentalidad de la ordenación sacerdotal y la institución divina de una jerarquía eclesiástica, pero el concilio fracasó en el intento de hacer derivar completamente el ministerio a partir del sacrificio. De haberlo logrado, el obispado habría representado sólo una potestad de jurisdicción mayor que la del presbiterado. Para el concilio, es el obispo y no el sacerdote la auténtica referencia del ministerio. Sin embargo, el obispo también es pastor de la Iglesia local que le sea confiada. Esta tendencia del concilio, que supera la comprensión puramente sacerdotal del ministerio, no llegó a imponerse en el tiempo subsiguiente a raíz de no haberse pronunciado aquél sobre la esencia del ministerio episcopal.

En la sesión XXIV, 11 de noviembre de 1563, se definió la sacramentalidad del matrimonio, si bien tampoco se definió la esencia de este sacramento de una forma dogmáticamente más pormenorizada, ni asimismo se respondió la cuestión de la institución del mismo por parte de Cristo. Tras vehementes discusiones, el decreto Tametsi vinculó la validez del matrimonio a la observación 
de la forma obligatoria o consenso de los contrayentes frente al párroco y dos testigos.

Los decretos de reforma de mayor alcance del concilio de Trento fueron despachados en el último medio año de sesiones. Cabe mencionar entre ellos el decreto sobre los seminarios — sesión XIII, 15 de julio de 1563—, que encargó a los obispos la creación de seminarios, sin que esta medida se opusiese a la existencia de facultades universitarias, y los dos paquetes de reformas de las sesiones XXIV y XXV, 11 de noviembre y $3 / 4$ de diciembre del mismo año. Fue mérito de Morone el haber encaminado el gran proyecto de reforma y haberlo llevado a buen puerto a través de todas las alternativas que se presentaron en el campo de fuerzas de la política. Gracias a su habilidad diplomática logró vincular al acontecer conciliar los diferentes intereses en pugna - Papa, curia, emperador, España, Francia...-, y neutralizarlos de tal modo que pudo lograrse el compromiso de una obra de reforma. Las definiciones más descollantes del concilio tienen que ver con el nombramiento de personas adecuadas como obispos y con la inquietud de mejorar la calidad de los ministros de la Iglesia. El anuncio de la fe debía colocarse nuevamente en primer plano, y visitas episcopales periódicas, sínodos diocesanos y concilios provinciales debían servir para asegurar las reformas. El decreto sobre las órdenes tuvo la intención de superar las irregularidades existentes en los monasterios. Las determinaciones sobre indulgencias, sobre el culto a la Virgen, santos, reliquias e imágenes procuraron encauzar la piedad popular por caminos adecuados y ordenados, y el deseo de elevar el nivel de la pastoral se extiende como un hilo conductor a través de muchos de los decretos de reforma.

En la sesión XXV, la conclusiva, los decretos despachados anteriormente fueron leídos y firmados por los padres conciliares, y se confió al Papa la confección del Índice de los libros prohibidos, del catecismo, del misal y del breviario. Pío IV confirmó el 26 de enero de 1564 verbalmente los decretos conciliares, cuya confirmación escrita refrendaba la Bula Benedictus Deus el 30 de junio de 1564.

En cuanto a la importancia del concilio de Trento, éste vio su tarea en confrontar la doctrina de la fe católica con las enseñanzas de los reformadores.

En efecto, en el enfrentamiento con los protestantes se produjo en reiteradas ocasiones una profunda reflexión sobre las propias posturas teológicas, y, en parte, también una primera formulación global de determinadas doctrinas como, por ejemplo, la de la justificación. La fijación de la propia identidad teológica era necesaria frente a los desafíos de la Reforma. Sin embargo, el trabajo teológico tuvo lugar muchas veces bajo el aspecto del confesionalismo, esto es, se procuró establecer una clara delimitación respecto del opositor de otra confesión. En dicho marco, se rechazaron valiosos impulsos que provenían de una te- 
ología de cuño humanista orientada más por la Biblia y la Patrística, y defendida por Contarini, Pole, o el varias veces mencionado Seripando, por temor a acercarse demasiado al bando contrario; y en el campo de la eclesiología, el pensamiento se aferró a cuestiones esenciales como el ministerio episcopal o el primado papal, a raíz de las oposiciones internas en el catolicismo.

Por otra parte, el concilio despachó decretos de reforma de gran alcance, pero la reforma tridentina en cuanto tal fue un compromiso. Una debilidad de ese compromiso consistió en que, pese a intervenir en determinadas competencias y prácticas de la curia romana, el concilio no quiso hacerlo de forma directa en la organización misma de la curia, en sus autoridades y tribunales, negativa que operó a menudo como un impedimento para la puesta en práctica de las resoluciones conciliares, ya que las medidas de los obispos podían ser socavadas mediante dispensas y exenciones papales. La obra de reforma quedó «en la zaga de presentación de objetivos no sólo de reformadores conciliaristas y galicanos, sino también de los jefes del movimiento católico de reforma del siglo» ${ }^{10}$. Lo que más llegó a realizarse de los decretos de reforma del concilio tridentino, y tuvo los mayores efectos, fue la elevación del nivel intelectual y espiritual del clero, y, por ende, una mejora de la pastoral.

Por último, y en lo relativo a su influencia y recepción, los decretos sobre la fe constituyeron en el tiempo subsiguiente a la terminación de la reunión de Trento la base para la formación de una identidad católica en la época de la confesionalización. La realización de las orientaciones de los decretos de reforma fue un asunto sumamente complejo y con diferentes niveles de incidencia. En verdad, la historia de su repercusión y acogimiento es muy diferente en los distintos países, diócesis y órdenes religiosas. El concilio ofreció un recurso para la reforma de la Iglesia, pero lo que tuvo un impacto modificador fue la atmósfera de una cierta mentalidad de reforma, ya preexistente por lo demás como vimos, y que no emanó sólo del concilio, sino que estuvo inspirada por todas las fuerzas renovadoras de la Iglesia. En la realización de las reformas tuvieron particular importancia, más allá de numerosas personalidades individuales, también las órdenes religiosas renovadas o de reciente fundación, como los jesuitas o los capuchinos; $\mathrm{y}$, desde luego, y aunque obviamente también con sus límites, contribuyó de forma esencialísima a dar forma a la Iglesia católica de más allá de la primera época moderna ${ }^{11}$. En este sentido, también Trento fue el máximo exponente y eje de un conjunto amplio y estructurado de movimientos, instituciones e iniciativas de la Iglesia católica, apostólica y romana conocido como Contrarreforma que surgido, en efecto y como ya se ha indicado, a mediados del Quinientos para contrarrestar la extensión de la Reforma protestante, recuperar los territorios europeos que habían escapado a su control, y consoli-

\footnotetext{
10 H. JEDIN, Historia del..., IV/2, p. 281.

11 Walter KASPER et alii (dirs.), Diccionario..., 2005a, 2, pp. 1339-1349; 2005b, pp. 560-570.
} 
dar su hegemonía en aquellas zonas que mantuvieron la fidelidad al catolicismo; acelerado tras Trento; y sobre todo de prolongados efectos, alcanza, empero, su más plástica y gráfica manifestación, expresión y concreción en la religiosidad y ambientación, compendio frecuente de recelos, intolerancia, cuando no palpable beligerancia, de la España/Europa del Barroco ${ }^{12}$.

\section{LA EuCARISTía EN El DEBATE TEOLÓGICO}

Como acabamos de ver, la sesión XIII del concilio tridentino despachó un decreto sobre la doctrina de la eucaristía con la definición de la presencia real y de la transubstanciación, si bien los artículos sobre la comunión bajo ambas especies fueron pospuestos hasta la llegada de los protestantes, lo que sucedió en la sesión XXI, en que asimismo se aprobó otro decreto sobre la comunión bajo ambas especies en el que se afirmaba que los laicos y los sacerdotes no celebrantes no están obligados por derecho divino a la comunión con el cáliz - comunión bajo ambas especies para los laicos-, y que Cristo está presente de forma plena y completa bajo cada una de las especies.

Igualmente, por su indudable relación con la eucaristía, recuerdo y actualización sacramental constante del sacrificio de Cristo según su mandato en la cena previa a su Pasión, se asumió en la sesión siguiente, 17 de septiembre de 1562, el decreto sobre la Misa, definida como verdadero y auténtico sacrificio, como recoge el mismo Mouchy en De Veritate Christi, el verdadero sacrificio de expiación que, en esa genuina comunidad intercomunicativa que para el catolicismo es la comunidad de fieles, opera por vivos y muertos, pero un sacrificio que es representación, memoria y aplicación del realizado en la cruz, e identificándose el sacrificio de la cruz y el de la misa, y sólo diferenciándose el modo del sacrificio.

También sabemos que para Lutero la eucaristía es consubstanciación; para Calvino, un medio de comulgar con la sustancia del Salvador al no admitir la presencia real de Cristo, en lo que también coincidirá el anglicanismo; para Zwinglio, un mero signo externo; así como de las polémicas al respecto de ubicuitarios y utraquistas, de la controversia sobre la Cena del Señor, o de la antedicha comunión bajo las dos especies. Está claro, pues, que la eucaristía, y sobre todo la afirmación o no de la presencia real de Cristo en ella y la aceptación o no de la comunión bajo ambas especies, verdaderas piedras de toque entre protestantismo y catolicismo, se sitúa en el centro mismo del debate teológico durante el Quinientos, como analizaré con detalle.

Por otra parte, conviene aclarar que eucaristía se asocia a «comunión», y, por extensión, y como ya se ha visto, a la misma misa, dada la antedicha defini-

12 LORTZ, Historia de la..., II, pp. 217-267. 
ción de sacrificio que le reconoció Trento, y su identificación con el de Cristo; la actualización y realización siempre de aquel sacramento en su transcurso, hasta el punto de que, generalizadamente, se habla de misa como sinónimo de eucaristía; y, sobre todo, la frecuente implicación teológica de ambos conceptos en la reforma, como veremos.

Se entiende por comunión, palabra procedente de la latina communio, y ésta a su vez correspondiente a la griega koinonia designante de la acción de unir y participar, la unión de las personas con Dios. Desde la perspectiva eucarística, significa la participación de los fieles en el cuerpo y la sangre de Cristo, aunque también tiene connotación de unión con la Iglesia, por lo que el término excomunión designa su exclusión. Con el nombre de comunión se llama asimismo al sacramento de la eucaristía — uno de los tres de iniciación cristiana junto al bautismo y la confirmación-, aunque desde muy pronto se estructuró este sacramento con una primera parte de escucha de la Palabra y una segunda de plegaria eucarística y comunión. Desde el siglo IV se fue generalizando el uso de composiciones litúrgicas escritas en latín, que conformaron el canon que ha permanecido hasta el concilio Vaticano II, siendo a partir de Trento cuando se insiste en la comunión diaria o periódica, antes poco frecuente y reservada tradicionalmente a ocasiones excepcionales ${ }^{13}$.

Por ende, y en consecuencia con lo indicado, se entiende por misa el acto de celebración litúrgica del sacramento de la eucaristía en el catolicismo, oficiado por un sacerdote en un altar, al que deben acudir todos los fieles según lo ordenan los mandamientos de la Iglesia católica. Término procedente del latino missa que significaba originariamente la bendición de despedida que se daba en el servicio religioso, quedó a partir de la reforma protestante adscrito al servicio eucarístico del catolicismo, que admite la transubstanciación del pan y el vino en el cuerpo y la sangre de Cristo, como veremos. Asimismo, en un principio la Iglesia sólo consideraba el domingo como día de sacrificio y celebración eucarística, pero ya en el siglo IV se celebran en muchas partes misa diaria, al tiempo que se iban generando y desarrollando los ritos de las iglesias oriental y occidental, siendo en ésta última donde acabó por imponerse el rito romano o latino, consagrado definitivamente en 1570 con la publicación del misal de Pío V, cuyo uso fue obligatorio para toda la Iglesia católica. Como se recordará, poco antes el concilio de Trento había promulgado en su sesión XXII los decretos que reformaban los desórdenes que durante época medieval se habían introducido en la misa, sobre todo la falta de decoro de los sacerdotes, los rasgos supersticiosos y los abusos económicos ligados a los estipendios, así como la prohibición absoluta de celebrar misa en lengua vernácula; ritual que ha permanecido prácticamente invariable hasta el concilio Vati-

13 E. Martínez Ruiz, Diccionario de..., pp. 83, 238. 
cano II, que reformó por completo la estructura de la misa y quedar como la conocemos hoy ${ }^{14}$.

Para terminar esta aportación, examinemos, pues, todas estas cuestiones, una vez establecido el indispensable marco conceptual.

En efecto, y como ya también adelanté, en el punto que nos ocupa para Lutero y el luteranismo la consubstanciación es la base de su fe en la Eucaristía, y consiste en entender ésta como la unión sacramental del cuerpo y la sangre de Cristo con la sustancia del pan y del vino consagrados, la coexistencia del cuerpo de Cristo con ambas sustancias. De esta forma el alemán está conforme con el dogma católico de la presencia real de Cristo en la eucaristía, aunque, y esta distinción es fundamental en Lutero, propugna resueltamente que con el cuerpo y la sangre de Cristo se conserva también la sustancia del pan y del vino - de ahí el nombre de su propuesta teológica-, que, por supuesto, deben tomarse comunión bajo ambas especies para los laicos-.

Este principio tiene varias explicaciones, entre las que se encuentran la de los «ubiquistas», «ubicuistas» $\mathrm{o}$ «ubicuitarios», quienes apelaban a la teoría de la ubicuidad del cuerpo de Cristo, y que también asume Lutero; la de quien, con el reformador también alemán Osiandro, admitía una extraña unión hipostática de Cristo con el pan y el vino que llamaban «impanación»; o la de, simplemente, quienes pretendían la existencia simultánea del cuerpo y la sangre de Cristo con la sustancia material del pan y del vino, que se juntaban entre sí. Lógicamente, todas ellas están en abierta contradicción con la teología y la tradición católicas, que admite en la institución de la eucaristía, como ya dijimos y sabemos, que cuando Cristo pronunció «éste es mi cuerpo», hacía referencia al cuerpo que veían los apóstoles, y no a uno inerte que se hubiera juntado con el pan y el vino. También así la tesis de Lutero sería rebatida por Zwinglio, quien se planteaba que o bien había que admitir con los católicos la transubstanciación, o bien negar con los sacramentarios la presencia real de Cristo en la eucaristía ${ }^{15}$. Pero para Lutero la eucaristía o «Cena del Señor», expresión utilizada por el reformador alemán a partir de 1522 para designar aquel culto de la comunidad cristiana cuyo origen se sitúa expresamente en la Ultima Cena de Cristo con sus discípulos - que sin embargo rechaza el catolicismo por considerar que reduce el acontecimiento del culto eucarístico, al circunscribirlo demasiado a la comida de la noche, y quizás implicar, equívocamente, que se trata de una mera representación de la Última Cena de Jesús-, y muy unida igualmente al mismo principio luterano de la ubicuidad otorgado a la naturaleza de Cristo, es la «comunión con Cristo y con todos los santos, abre el testamento de Cristo crucificado y reparte su herencia, la promesa del perdón de los peca-

14 E. Martínez RuIz (dir.), Diccionario de..., p. 185.
15 Ibid., p. 99.

Hispania Sacra, LVIII

118, julio-diciembre 2006, 489-515, ISSN: 0018-215-X 
dos, dando así certeza a dicha promesa» ${ }^{16}$. Tres principios son, por ende, axiales en Lutero y el luteranismo: La «Cena del Señor», origen de toda una controversia teológica; la doctrina de la ubicuidad, fuste de aquélla y seguida luego por ubiquistas, ubicuistas o ubicuitarios; y la comunión bajo ambas especies. Veámoslos pues.

En lo concerniente a la Cena del Señor y su polémica, durante la tardía Edad Media muchos teólogos consideraban todavía, junto con Ockham, que la consubstanciación, coexistencia de las sustancias inalteradas del pan y del vino con el cuerpo y la sangre de Cristo como sabemos, era una alternativa teológica no sólo posible sino también más convincente y con menos dificultades que la transubstanciación, si bien siguieron sosteniendo ésta última a raíz de la decisión de la Iglesia. En oposición a ellos, el teólogo inglés del siglo XIV John Wyclif rechaza decididamente la transubstanciación, en particular, y siguiendo a Ockham, la difundida explicación de la misma como aniquilación de las sustancias del pan y del vino y su reemplazo por la sustancia del cuerpo y la sangre de Cristo. No obstante, sostiene también la presencia real de Cristo en el sentido de la coexistencia o concomitancia, aunque acentúa con énfasis su significado sacramental y espiritual, para distinguirla de una presencia de tipo local-espacial. La descripción del sacramento como signo eficaz muestra nítidamente la influencia del pensamiento de San Agustín. Wyclif rechaza tanto una identificación indiferenciada entre el sacramento y el cuerpo de Jesucristo, cuanto la «empanación» - hacerse pan, en una suerte de paralelo análogo a la encarnación-. Pese a la fuerte influencia que recibió de Wyclif, su contemporáneo y también teólogo bohemio Jan Hus no hizo propio su rechazo de la transubstanciación, y en el concilio de Constanza refutó con vehemencia imputaciones en tal sentido. Tras estos enfrentamientos, el tema se retoma en plena reforma protestante.

En efecto, tal como se planteó en la época de la Reforma, el núcleo de la controversia luterano-católica sobre el sacramento del altar está dado por la cuestión de si la Cena del Señor en lugar de ser un don de Dios a la Iglesia, es obra de ésta última. En 1520 Lutero quiso liberar a la misa de la «cautividad» que significaba el hecho de ser concebida como un sacrificio ofrecido por el sacerdote. Aún en 1537 en los Artículos de Esmalcalda la misa comprendida como «sacrificio y obra» parece a Lutero la mayor y más tremenda atrocidad, opuesta al artículo principal de la justificación. No obstante, Lutero describe la Cena del Señor como «sacrificio de alabanza» de la comunidad, por lo que le reconoce, en tal sentido, carácter eucarístico. Pese a estas diferencias, existe entre Lutero y el catolicismo una cercanía objetiva en la cuestión de la presencia real de Cristo en la santa Cena, aun cuando aquél rechaza la teoría de la tran-

16 W. KASPER et alii (dirs.), Diccionario..., 2005b, p. 352. 
substanciación como sabemos. En su celebración de la Cena del Señor Lutero conservó la elevación de las especies pero eliminó el ofertorio, así como también las oraciones del canon que rodeaban las palabras de la institución. De esta forma, la celebración de la Cena del Señor se concentra en la recitación de las palabras de la institución y en la recepción de los dones por parte de quienes comulgan.

En la tradición reformada, los acentos recaen más sobre la idea de la confesión de fe y de la memoria de Jesucristo celebrada en la Cena del Señor, especialmente en Zwinglio. Por lo demás, la comprensión de la Cena del Señor en la tradición reformada se caracteriza sobre todo por el enfrentamiento con la comprensión luterana de la presencia real: Yendo más allá de Zwinglio, Calvino enseñará que Cristo se hace presente para la fe a través del Espíritu Santo de forma paralela al acto de comer y beber el pan y el vino, pero hay coincidencia con el luteranismo en el vehemente rechazo de la misa como sacrificio expiatorio ofrecido por el sacerdote.

Por su parte, el anglicanismo, aun rechazando la comprensión de la Cena del Señor como sacrifico de expiación, conservó más elementos del rito tradicional, conteniendo aun una oración en que la Iglesia hace un acto de ofrecimiento de sí misma.

La primera gran disputa se produjo de 1525 a 1529 entre Lutero y Zwinglio. Impresionado por las palabras de la institución, Lutero sostuvo siempre la presencia real del cuerpo y la sangre de Cristo, y, rechazando la transubstanciación, entendió tal presencia como consubstanciación, como sabemos. Ya antes de la controversia propiamente dicha, en la delimitación teológica frente a los Hermanos Bohemios y, especialmente, frente a la importante doctrina del jurista holandés Cornelis Hoen sobre la santa Cena, Lutero puso cada vez más en primer plano la presencia real y, a diferencia del también reformador alemán Andreas Karlstadt, acentuó la importancia de la Cena del Señor como medio comunicador de gracia. En cambio, Zwinglio negó expresamente la presencia real de la naturaleza humana de Cristo en el sacramento, que como «signum», no transmite la gracia sino sólo la acción salvífica de Dios. Por su parte, los reformadores suizos atribuyeron su postura a Erasmo, atribución que éste rechazó como injustificada. En el contexto de la controversia, de fuerte tono polémico en ambos frentes, Lutero desarrolló precisamente la doctrina de la ubicuidad de la naturaleza humana de Cristo como ayuda para comprender, que no demostrar, la posibilidad de la presencia real de Cristo. La postura asumida frente a la «manducatio oralis» — consumición puramente corporal— y a la «manducatio impiorum» — consumición por parte de no creyentes- se convirtió para Lutero en la verdadera piedra de toque para la confesión de fe en la presencia real, y en este punto no pudo superarse la oposición doctrinal entre Lutero y Zwinglio. Por lo mismo también fracasó el Coloquio religioso de Marburgo, en octubre de 
1529, y tampoco la Concordia de Wittemberg, en 1536, logró una unión duradera y consistente entre los luteranos y las ciudades reformadas de la alta Alemania. Así, la unidad del protestantismo se quebró ante la cuestión de la presencia real de Cristo. Esto se presenta nuevamente con nitidez en el segundo gran enfrentamiento entre el teólogo luterano hamburgués Westphal y Calvino. Junto con la doctrina de la ubicuidad de Lutero, Calvino rechaza asimismo la presencia corpórea de Cristo en los elementos de la santa Cena, la manducatio oralis e impiorum, pero defiende una comprensión dinámica de la presencia eucarística. Para una descripción acertada de esta comprensión no es suficiente el concepto de presencia virtual, sino que es necesario el concepto de presencia espiritual de la persona y obra de Cristo, comunicada eficazmente por el Espíritu Santo a quien recibe la santa Cena con ánimo creyente. En este sentido habla Calvino de una presencia substancial y de una comunicación de la substancia de Cristo. La controversia, que no llegó a entendimiento y terminó con la condena luterana de la doctrina reformada sobre la Cena del Señor en la Fórmula de Concordia, en 1577, selló para los siglos siguientes la separación entre las iglesias del protestantismo ${ }^{17}$.

Por su parte, la doctrina de la ubicuidad, fundamento teológico luterano de la presencia real y corporal de Cristo en la Santa Cena, utilizada en el contexto de la controversia sobre la Cena del Señor, como acabamos de mostrar, y algo más que una mera teoría sobre ésta por cuanto debe verse en el contexto de toda la cristología de Lutero, defiende que la naturaleza humana de Cristo participa de los atributos divinos del Logos, razón por la cual puede estar corporalmente en todo lugar donde se administren los dones de la Santa Cena —ubique, nombre que designará precisamente a los seguidores de esta interpretación teológica, ubiquistas, ubicuistas o ubicuitarios - . La enseñanza de esta presencia corporal de Cristo fue fijada por escrito en la antedicha Fórmula de Concordia de 1577 y asociada a condenas doctrinales ${ }^{18}$.

Por último, y para concluir Lutero, la comunión bajo ambas especies para los laicos — sub utraque specie, de donde toman nombre los utraquistas, grupos operantes dentro de la reforma bohemia de los siglos XVI y XVII defensores de la recepción de la eucaristía bajo ambas especies como los husitas y calixtinos-, práctica usual en la iglesia antigua y medieval, y también desde el principio objeto de polémica al respecto, aunque nos centramos básicamente en la aportación luterana ${ }^{19}$.

Al comienzo de su misión, y en contra de los husitas, Lutero declaró que una división de la Iglesia a causa de la comunión de los laicos con el cáliz esta-

17 W. KASPER et alii (dirs.), Diccionario..., 2005b, pp. 107-111.

18 Ibid., p. 574. HugHES, 1999, online edit.

19 J. Hughes, 1999, online edit. W. KASPER et alii (dirs.), Diccionario..., 2005b, p. 577. 
ba injustificada. Sin embargo, más tarde él mismo exigió la comunión bajo ambas especies como acción conforme con la Sagrada Escritura. Como la exigencia de Lutero se convirtió en un medio de lucha de los protestantes contra la Iglesia católica, algunos príncipes católicos como los de Baviera y Habsburgo, y algunos teólogos como Cochlaeus, Pflug o Witzel, vieron en la concesión de la comunión bajo ambas especies un medio para detener en parte la apostasía del catolicismo. El cardenal Tomás de Vío Cayetano se había manifestado en un informe dirigido al Papa a favor del permiso del cáliz para los laicos, mientras Carlos V permitía en el Interim de 1548 a los protestantes alemanes la comunión bajo ambas especies hasta que un concilio decidiera al efecto. A su vez, el de Trento, en su sesión XXII, 17 de septiembre de 1562, transfirió la decisión sobre el tema al Papa, siendo precisamente Pío IV quien dos años más tarde, el 16 de abril de 1564 concretamente, otorgó, urgido por el ya entonces emperador Fernando I y el duque Alberto V de Baviera, el «Indulto del cáliz» para Alemania, Austria, Bohemia y Hungría, si bien el interés por su aplicación no demostró ser demasiado intenso. En todo caso, y como quiera que a esas alturas del Quinientos la delimitación confesional había avanzado mucho, el duque de Baviera suprimió nuevamente la comunión bajo ambas especies para su territorio en 1571, Austria siguió su ejemplo en 1584, y en este mismo año Gregorio XIII derogó el indulto, prohibiéndose el cáliz para los laicos nuevamente por el papado para Hungría en 1604 y para Bohemia en 1621, opción que sólo desde 1963, y siempre en casos a determinar por la Sede Apostólica, se ha restablecido al determinar el Vaticano II que los obispos tienen el derecho de permitir también a los laicos la comunión bajo ambas especies ${ }^{20}$.

Como habrá podido ya suponerse, obviamente el cuerpo teológico fundamental sobre la eucaristía antes de Trento es el luterano, al que completaron o puntualizaron Zwinglio, Calvino, y el anglicanismo. Repasemos, pues, estas últimas propuestas.

En su intransigente oposición a la liturgia y ceremonias católicas romanas y en su no menos contundente interés en simplificar el culto, Zwinglio siempre vio el sacramento de la eucaristía como un mero signo externo, concepción simbólica de la santa cena defendida precisamente en su disputa con Lutero. Para el reformador suizo la transmisión de la salvación no depende de los elementos, sino sólo de Dios, que regala la fe en Cristo como Hijo de Dios. Cristo está presente según su naturaleza divina, pero, según su naturaleza humana, está sentado a la derecha de Dios, de forma que entiende las palabras de la institución — «este es mi cuerpo...»— en el sentido de «significar», y la expresión «comer a Cristo» (Jn. 6) designando, para él, creer en Jesucristo. En la cena

${ }^{20}$ H. Jedin, Historia del..., IV/1, pp. 247-305. J. Hughes, Ibid., online. W. KASPER et alii (dirs.), Diccionario..., 2005a, 1, pp. 280-282; 2005b, pp. 120-121, 577.

Hispania Sacra, LVIII

118, julio-diciembre 2006, 489-515, ISSN: 0018-215-X 
del Señor los fieles recuerdan el sacrifico único de Cristo, dan gracias - eucaristía - por la salvación obrada por Dios, y confiesan al mismo tiempo su comunión con Cristo, obligándose mutuamente a llevar una vida digna, siendo fundamental la fe en Cristo como Hijo de Dios, que, como se decía, está presente según su naturaleza divina, pero que, según su naturaleza humana, está sentado a la derecha de Dios. Precisamente esta concepción de Zwinglio sobre la presencia de Cristo en la santa cena hizo fracasar su entendimiento con Lutero en el Coloquio de Religión de Marburgo de 1529, siendo la Confessio Helvetica Prior de 1536, portadora esencialmente de la impronta del pensamiento del sucesor de Zwinglio en Zurich, Bullinger, y asumida por los estamentos protestantes de la Confederación Helvética, la que confirmó en lo sustancial la concepción simbólica de la santa cena ${ }^{21}$.

Por su parte, y como también ya sabemos, la interpretación calvinista de la eucaristía niega la presencia real de Cristo, si bien su mentor defendió que en la Cena del Señor se da verdaderamente Cristo a través de los signos del pan y del vino, para que formemos con Él un solo cuerpo. Esto supone que Calvino sostiene una concepción dinámica de la presencia real y de la transformación de las especies en la Cena del Señor: Los elementos, signados por la Palabra de Dios, pasan a ser algo «que antes no eran». «Decimos que Cristo desciende a nosotros tanto en el símbolo externo como también en su Espíritu, a fin de vivificar verdaderamente nuestras almas con la sustancia de su carne y de su sangre», aclaraba el teólogo francés. Según Calvino, pues, la eucaristía, como el bautismo, son acciones de comunicación en las que Dios se «adapta» y permite experimentar sus «bienes espirituales» a través de medios físicos ${ }^{22}$.

Por lo demás, la concepción calvinista de la eucaristía es particularmente difícil de exponer, porque es muy matizada y parece haber ido evolucionando a lo largo de la vida del reformador. Para comprenderla deben tenerse presentes cuatro puntos.

En primer lugar, que Calvino fue muy sensible a los desacuerdos surgidos entre los protestantes a propósito de la presencia real. Se esforzó, por tanto, en conciliar las diferentes tesis que entonces se mantenían, causa, según su propia confesión, de su tardanza en adherirse a la reforma. En segundo lugar, que Calvino permaneció fiel a la cosmogonía medieval que representaba a Cristo resucitado «sentado con toda majestad» a la diestra de Dios Padre, por lo que Calvino tendía a situar la ubicuidad de Jesús en las especies para «preservar su materialidad en el cielo». No obstante, y en tercer lugar, su piedad cristocéntrica exigía una unión salvadora de Cristo y el hombre; no podía admitir que las palabras de la institución de la cena fueran simples símbolos. Finalmente, hay

\footnotetext{
21 W. KASPER et alii (dirs.), Diccionario..., 2005a, 2, pp. 1395-1396; 2005b, p. 624.

22 Ibid., 2005b, p. 82.
} 
que tener en cuenta que el reformador usó los términos sustancia y sustancial unas veces en el sentido tradicional, y otra con un sentido nuevo, lo que complica aún más la correcta interpretación de su doctrina en esta materia, llegando incluso a sospecharse, leyendo algunos de sus escritos al respecto, que aceptaría la consubstanciación luterana.

En definitiva, la concepción calvinista de la cena es la siguiente: El pan y el vino no se transforman en ningún momento en el cuerpo y la sangre de Cristo, pero son los instrumentos, los signos y el medio por los que los fieles comulgan realmente con la sustancia de Cristo. Por sustancia hay que entender no propiamente el cuerpo crucificado de Cristo, sino lo esencial de su naturaleza humana, esto es, la espiritualidad y los dones, la fuerza y las virtudes de Jesús hecho hombre. La comunión no es, por tanto, una ceremonia simbólica, como dirá Zwinglio, ni la ingestión material del cuerpo y la sangre de Cristo, como enseñaba Roma y Lutero, sino la participación real en la vida y en los beneficios del Dios hombre, solución de compromiso entre el objetivismo católico y luterano, y el simbolismo zwingliano. Pero Calvino, que aparentemente estaba, respecto a este tema de la Cena, más próximo a las concepciones luteranas que a las de Zwinglio, llegó a un acuerdo con su consabido sucesor en Zurich, Bullinger. Percatándose de lo inestable de su posición en Ginebra, comprendió la necesidad de hallar aliados. En el célebre Consensus tigurinus de 1549 aceptó que se suprimieran los términos sustancia y sustancial, aunque en su enseñanza y escritos posteriores Calvino siguió manteniendo, contra la opinión de Bullinger, la expresión «presencia real» y «comunicación esencial e inefable» de Cristo en la cena. Por si esto fuera poco, los estudiantes de la Academia de Ginebra tuvieron que aceptar una Confesión en la que figuraba el término «sustancializar». No obstante, Calvino defendió el Consensus frente a los luteranos y especialmente contra el ya en otro momento citado teólogo hamburgués Westphal, de manera que, tras la muerte de aquél, todas las iglesias reformadas de Suiza, salvo la de Basilea, aceptaron una Confesión helvética de carácter zwingliano, establecida en 1562, en la que las doctrinas calvinistas sobre la cena y la predestinación no tenían cabida. La larga lucha sostenida por el reformador de Ginebra acabó con la victoria del sacramentalismo, mas es preciso subrayar que la reforma zwinglio-calvinista, o simplemente calvinista, dispuso desde el Consensus de Zurich de fuerzas nuevas para extenderse por Inglaterra, Francia, Países Bajos, Alemania y más allá de Alemania ${ }^{23}$.

Por último, el Anglicanismo defiende el símbolo de la eucaristía y la comunión sin reconocer la transubstanciación, aunque este último punto estuvo sujeto a variación según las distintas fases por la que aquella reforma pasó; así, se afirmó en la Confesión de fe de los Diez artículos, en 1536, y en el Acta para

23 J. Delumeau, La reforma, pp. 71-73. E. Martínez Ruiz (dir.), Diccionario de..., p. 46.

Hispania Sacra, LVIII

118, julio-diciembre 2006, 489-515, ISSN: 0018-215-X 
abolir la diversidad de opiniones, en 1539, castigándose incluso con la hoguera a quienes la negaran, y donde se declaraba inútil para los laicos la comunión bajo las dos especies. Habrá que esperar justamente a la reimplantación y consolidación del Anglicanismo con Isabel I para que éste quede conformado. En concreto en el punto que nos ocupa, y dada la proximidad de la fe anglicana en esta su última etapa a Calvino, el sacramento de la cena es entendido en el sentido de éste, esto es, una comunión real pero espiritual con Cristo, y sin poder ser nunca un sacrificio ${ }^{24}$.

Y en todo este panorama llegó Trento.

Siendo, en efecto, la católica la última de los grandes movimientos de reforma del Quinientos, obviamente el concilio tridentino dedicó buena parte de sus esfuerzos, debates y desvelos a uno de los dos únicos sacramentos reconocidos por el protestantismo, por supuesto crucial para la fe cristiana católica, intrínseca y genuinamente unido al mismo concepto de la misa, y tan reinterpretado antes de la inauguración de Trento, y también después, como hemos visto ${ }^{25}$.

Como ya sabemos, la afirmación fundamental del catolicismo en el tema que nos ocupa es la transubstanciación, acto por el que, en la eucaristía, la sustancia del pan y el vino se transforma realmente en el cuerpo y la sangre de Cristo; principio nuclear en el culto de la Iglesia católica, apostólica y romana definido en el concilio de Trento; y radical y absoluta distinción con el protestantismo, que, como ya hemos visto, no sólo rechaza su existencia, sino que también reduce la misa a una ceremonia meramente conmemorativa ${ }^{26}:$ «Si alguno dijere que en el sacrosanto sacramento de la Eucaristía permanece la sustancia de pan y de vino juntamente con el cuerpo y la sangre de nuestro Señor Jesucristo, y negare aquella maravillosa y única conversión de toda la sustancia del pan en el cuerpo y toda la sustancia del vino en la sangre, permaneciendo sólo las especies de pan y vino; conversión que la Iglesia Católica aptísimamente llama transubstanciación, sea anatema» (canon 2 del sacramento de la eucaristía, sacramento de fe para los católicos).

En efecto, inserto y partícipe de la misma construcción teológica que del sacramento crea Trento, enfatizando su fuerza y poder como «signos eficaces», en el de la eucaristía, objeto de amplias discusiones que se explican por la importancia que el Quinientos concedió al problema de la presencia real, y de las mismas varias opiniones protestantes al respecto ya vistas, la Iglesia romana mantiene la doctrina de la permanencia de la presencia real después de la consagración en todas las hostias que no han servido para comulgar - «real y esencial presencia» como declara Mouchy en su De Veritate Christi-. Por otra par-

\footnotetext{
24 J. Delumeau, Ibid., pp. 76-79.

25 J. Pohle y M. M- Hassett, 1999, online edit.

26 E. Martínez Ruiz (dir.), Diccionario de..., p. 257.
} 
te, refuta, contrariamente al deseo de muchísimos innovadores, que la eucaristía sea íntegramente distribuida entre los asistentes. Así pues, no admite el punto de vista luterano adoptado por todos los protestantes según el cual no se debe adorar a Cristo en la eucaristía, ni honrarlo mediante fiestas, ni pasearlo en procesiones, ni llevarlo a los enfermos, decisiones de muy importantes consecuencias para la piedad, las manifestaciones del culto y el arte religioso de las iglesias cristianas que, así, y como veremos, tomarían a lo largo de muchos siglos vías muy diferentes.

No obstante, y pese a su importancia, la palabra eucaristía, cuyo uso ha permanecido en el vocabulario católico, no es la que mejor expresa la teología romana en lo concerniente al problema de la misa. Ciertamente, aquélla no fue definida por el concilio de Trento como una simple «acción de gracias», sino como un sacrificio, como también ya sabemos y recoge oportunamente el $D e$ Veritate Christi, y este hecho era justamente lo que la reforma protestante refutaba. Para Lutero y sus discípulos creer que el sacerdote, en el acto de la misa, ofrece nuevamente el Hijo de Dios a Dios Padre es blasfemar el sacrificio de la cruz que de una vez por todas fue llevado a cabo por el único que podía ofrecerlo, Jesús. En el concilio una minoría, a la que pertenecía Seripando, mantenía la opinión de que la misa no es un verdadero sacrificio, pero la mayoría sustentaba la opinión contraria, apoyándose principalmente en una profecía de Malaquías al respecto (I, 11): «Desde Levante a Poniente, mi Nombre es grande en todas las naciones y en todo lugar se ofrece a mi Nombre un sacrificio de incienso y una ofrenda pura». Además, la para los católicos impresionante observación teológica de que si la misa no era un sacrificio, los cristianos carecerían de él, con lo cual serían más desgraciados que cualquier pagano, ya que no puede citarse nación pagana alguna que carezca de sacrificio, hizo que los padres del concilio afirmaran que en la cena Jesús no se ofreció simplemente como alimento, sino que además fue inmolado místicamente, y que la misa, que ha sido instituida por el Salvador, hecho negado en la confesión de Augsburgo de 1555, aplica la saludable virtud del sacrificio de la cruz a la remisión de los pecados. Como además la misa sirve tanto a vivos como a aquellos que han muerto en Cristo y aún no han sido purificados, quedan plenamente justificadas las misas «privadas». El canon fue declarado exento de errores y seducciones, pero debía ser dicho en voz baja y en latín, la lengua litúrgica ${ }^{27}$.

Llegar a este encuentro no fue sencillo ni fácil: Fueron necesarias numerosas intervenciones que tuvieron lugar durante sesudos y complejos debates y en los que destacaron varios teólogos franciscanos españoles como Juan Ramírez, Francisco Orantes, el bien conocido Benito Arias Montano, Diego Laínez, Pedro de Soto, o Antonio de San Miguel; la aprobación del decreto sobre la doc-

27 J. Delumeau, El catolicismo..., pp. 15-18.

Hispania Sacra, LVIII

118, julio-diciembre 2006, 489-515, ISSN: 0018-215-X 
trina católica de la eucaristía con la definición de la presencia real y de la transubstanciación en la sesión tridentina XIII del 11 de octubre de 1551; el examen teológico, el 7 de junio de 1562, de los cinco puntos referentes al uso de la comunión que ya anteriormente habían sido muy discutidos, y a los que pertenecía la tan repetida cuestión sobre la comunión bajo las dos especies, que casi por unanimidad se decidió negativamente, y que fueron la base de la sesión conciliar XXI; el desarrollo concreto de ésta el 16 de julio de 1562, y el de la XXII, el 17 de septiembre, centrada en la misa, definida como verdadero sacrificio como ya sabemos; y, por supuesto, la proclamación del decreto conciliar sobre la eucaristía, compuesto de un preámbulo, ocho capítulos doctrinales y once cánones que cristalizaban todo lo que ya hemos analizado, defendían los padres conciliares, y, con tan sólo las lógicas adaptaciones a los tiempos, constituyen la médula del sacramento eucarístico en el catolicismo hasta el presente, a saber: De la presencia real de nuestro Señor Jesucristo en el santísimo sacramento de la eucaristía; razón de la institución de este santísimo sacramento; de la excelencia de la santísima eucaristía sobre los demás sacramentos; de la transubstanciación; del culto y veneración que debe tributarse a este santísimo sacramento; que se ha de reservar el santísimo sacramento de la eucaristía y llevarlo a los enfermos; de la preparación que debe llevarse para recibir dignamente la santa eucaristía; y del uso de este admirable sacramento ${ }^{28}$.

Finalmente, y como ya apuntamos, para el mundo católico la nuclearidad del sacramento de la eucaristía tuvo como consecuencia la emersión o consolidación de determinadas manifestaciones de la religiosidad popular que lo exaltaron desde fines del Quinientos y durante todo el Antiguo Régimen, y aun hasta hoy, como la creación de las hermandades sacramentales, junto con las de ánimas, omnipresentes en toda parroquia; la floración de los autos sacramentales; y, cómo no, el enorme impulso alcanzado por la celebración del Corpus Christi, la única procesión general, al concurrir conjunta, pública y oficialmente cabildo civil y eclesiástico. En el caso de España, su especial devoción al sacramento eucarístico se ha traducido en muy diversas expresiones.

Así, la difusión de la eucaristía en la era patrística, destacando sobre todo san Isidoro de Sevilla, quien en su De ecclesiasticis officiis expuso su doctrina sobre el sacrificio eucarístico y la naturaleza del mismo, y en las Etimologías, la noción de sacrificio, haciéndola derivar de sacrum factum, y que en la eucaristía es sacramento el cuerpo y la sangre de Cristo; pero también la presencia real aparece en san Dámaso, o en Prudencio. En cuanto al concilio de Elvira, en el 305, es conocida la nota rigorista de uno de sus cánones prohibiendo dar la comunión, aun al fin de la vida, a los adultos que, tras el bautismo, hubieran sa-

28 E. DenZINGER, El magisterio de la .., pp. 244-250, 267-271. H. Jedin, Historia del..., III, pp. 5986, 403-436, 503-522; 4/1, pp. 307-365. Bernardino LlORCA, «Participación de...», pp. 467-473. C. GutiÉRrez, Trento: Un..., III, pp. 103-144. Juan Luis ACEBAl et alii, Código de..., pp. 482-504. 
crificado a los ídolos, rígida disciplina que fue moderada luego en los concilios de Ancira y Nicea.

Los ya mencionados autos sacramentales de nuestra literatura de los siglos XVI y XVII en donde han jugado tan importante papel por sus relaciones con las fiestas del Corpus. Comenzaba su representación en la tarde de dicho día y se extendía durante la octava. Iniciados con escenas eucarísticas ideales en loa del misterio de la Cena, con personajes y argumentos verosímiles, pidieron después argumentos a la historia y a los personajes más famosos por su devoción al Santísimo, y acabaron acudiendo a la representación de alegorías y símbolos, si bien no siempre los «autos» fueron rigurosamente eucarísticos con materia estrictamente tal, en alabanza del sacramento. Unas veces son eucarísticos por su finalidad, y otras, por la ocasión de la fiesta eucarística en que se representaban, pero siempre perseguían instruir al pueblo y comunicarle la teología, de la que gustaba, en este caso, sobre la eucaristía.

Y, por supuesto, las tradiciones eucarísticas españolas, comenzando por el bien conocido y cotidiano saludo del «alabado sea el Santísimo Sacramento del altar»; otras costumbres populares como el baile de los «seises» en la catedral sevillana; las artes en relación con la eucaristía; los famosos Congresos Eucarísticos; los autores que escribieron sobre la eucaristía, como los grandes teólogos Toledo, Maldonado, Suárez, Lugo, o los ascéticos Cristóbal Madrid, Luis de la Puente, san Juan de Ribera, y muchos otros; o las devociones a los santos distinguidos por el culto al Santísimo, donde descollaron san Juan de Ávila, san Ignacio de Loyola, y, sobre todo, san Pascual Bailón, patrono de los Congresos Eucarísticos, de tan acendrada raigambre en nuestro país ${ }^{29}$.

\section{BIBLIOGRAFÍA}

Acebal, J. L. et alii (colabrs.), Código de Derecho Canónico. Edición bilingüe comentada, Madrid, 2001.

Aldea Vaquero, Q.; Marín Martínez, T., y Vives Gatell, J. (dirs.), Diccionario de Historia Eclesiástica de España, II, Madrid, 1972.

BATAILLON, M., Erasmo y España. Estudios sobre la historia espiritual del siglo XVI, Méjico, 1966.

Delumeau, J., El catolicismo de Lutero a Voltaire, Barcelona, 1973.

- La reforma, Barcelona, 1977.

29 Quintín Aldea Vaquero, Tomás Marín Martínez y J. Vives Gatell (dirs.), Diccionario de..., II, pp. 880-2. 
DenZinger, E., El magisterio de la Iglesia. Manual de los símbolos, definiciones y declaraciones de la Iglesia en materia de fe y costumbres, Barcelona, 1963.

GutiÉRrez, C., Trento: Un concilio para la unión (1550-1552), III: Estudio, Madrid, 1981.

Hassett, M. M., «Primeros Símbolos de la Eucaristía», The Catholic Encyclopedia, I, 1999, Online Edition: URL: http://www.enciclopediacatolica.com

Hughes, J., «Ubicuitarios»; «Utraquismo», The Catholic Encyclopedia, I, 1999, Online Edition: URL: http://www.enciclopediacatolica.com

Jedin, H., Historia del Concilio de Trento, III: Etapa de Bolonia (1547-1548). Segundo periodo de Trento (1551-1552); IV: Tercer periodo de sesiones y conclusión, 1: Francia y la reanudación del concilio en Trento hasta la muerte de los legados Gonzaga y Seripando; 2: Superación de la crisis gracias a Morone, conclusión y ratificación, Pamplona, 1975, 1981, respectivamente.

KASPER, W. et alii (dirs.), Diccionario enciclopédico de Historia de la Iglesia, I-II, Barcelona, 2005a.

- Diccionario enciclopédico de la época de la Reforma, Barcelona, 2005b.

LORTZ, J., Historia de la Iglesia en la perspectiva de la historia del pensamiento, I: Antigüedad y Edad Media; II: Edad Moderna y Contemporánea, Madrid, 1982.

LlorCA, B., «Participación de España en el Concilio de Trento», en J. L. GoNZÁlez Novalín (dir.), Historia de la Iglesia en España, III-1. : La Iglesia en la España de los siglos XV y XVI, Madrid, 1980, 385-503.

Martín Hernández, F., Historia de la Iglesia, II: Edad Moderna, Madrid, 2000.

Martínez Ruiz, E. (dir.), Diccionario de Historia Moderna de España, I: La Iglesia, Madrid, 1998.

ORLANDIS, J., Historia de la Iglesia, I: La Iglesia antigua y medieval, Madrid, 1998.

PoHLE, J., «La Presencia Real de Cristo en la Eucaristía»; «Eucaristía»; «La Sagrada Eucaristía como Sacramento», The Catholic Encyclopedia, I, 1999, Online Edition: URL: http://www.enciclopediacatolica.com

Romano, R., y Tenenti, A., Historia Universal, 12: Los fundamentos del mundo moderno. Edad Media tardía, Renacimiento, Reforma, Madrid, 1983.

Teruel Gregorio de TejadA, M., Manual básico de la historia de la Iglesia, Barcelona, 1993. 